\title{
Decision-Making in the Police Work Force: Affordances Explained in Practice
}

\author{
Matthijs J. Verhulst ${ }^{1}$ (i) - Anne-Françoise Rutkowski ${ }^{1}$ \\ Published online: 10 August 2018 \\ (c) The Author(s) 2018
}

\begin{abstract}
Studies of decision-making in High Reliability Organizations as supported by Information Technology have mostly pertained to the "cold" context, that is, the planning and briefing tasks that precede intervention. Meanwhile, the degree of elasticity required of High Reliability Teams during critical processes is key to stabilizing team performance and can be enhanced through the use of technology. However, off-the-shelf technologies are often used in organizations without due consideration of their impact on task interdependence and affordance. This article presents the results from a threestep explorative field study that investigated the effects of the imbrication between human (e.g., users) and material (e.g., technology) agencies on the decision-making processes used by a police force. Particularly, we address the impact on the individual, collective, and shared affordances of mobile technology (i.e., smartphone) in terms of the daily work routine of officers on the streets. Teams of police officers were shadowed during their daily work for a period of 80 hours. This article presents the findings in the form of four vignettes. The approach used proved useful for determining the affordance of technology in relation to task interdependence on micro-processes and decision-making.
\end{abstract}

Keywords Group Support Systems · Sociomateriality · Affordances · Constraints · Imbrication · Collaborative technology · High Reliability Organizations

\section{Introduction}

Two important facets of decision-making are that it involves problem-solving and is task-related (Simon and Newell 1973). Decisions are a product of our individual

\footnotetext{
$\bowtie \quad$ Matthijs J. Verhulst

m.j.verhulst@tilburguniversity.edu

Anne-Françoise Rutkowski

a.rutkowski@tilburguniversity.edu

1 Department of Management, Tilburg University, Tilburg, Netherlands
} 
cognitive activities and are influenced by various psychological biases. For example, under uncertainty, individuals rely on a limited number of heuristics, which may yield either reasonable judgments or systematic errors (Tversky and Kahneman 1973; Klein 1999). The aim of this study is to explore material and human agency imbrication in decision-making in the context of the Dutch national police. Particularly focusing on incident response teams operating with smartphone technologies in the street.

Decisions tend to be assessed based on one's prediction of a multiplicity of outcomes, forming a causal chain of behavioral reactions. Overall, making them entails information processing, information structuring, problem-solving, and interpersonal communication. Each of these activities represents a succession of goal-driven cognitive and social micro-processes. The study of micro-processes involves "understanding how interaction is coordinated in ways that help to create shared understanding with a particular focus on shared symbolic systems among the participants in situ" (Burger et al. 2018). At the same time, decision performance is dynamic and time dependent (Brehmer 1992). In making decisions, humans apply the rules of logic and use their expertise, experiences, and associated emotions (Rutkowski 2016). Logic and "gut feelings" thus co-exist in the processing of information for decision-making. Accordingly, the process is a complex "fuzzy" activity — and the complexity and fuzziness of the decision-making process is accentuated when it involves multiple actors. Originally, Asch (1952) was one of the pioneers who considered the impact of the social environment on micro-processes. He compared group dynamics and group decisionmaking to the chemical compound $\mathrm{H} 2 \mathrm{O}$. That is, neither quantity is a simple aggregate of its constituents (e.g., hydrogen and oxygen); rather, the ultimate outcome is affected by their arrangement. The elements of hydrogen and oxygen can produce substances with vastly different characteristics - such as ice, water, steam-based on how they are organized. Analogously, collaboration can be seen as a complex aggregation of ideas that require specific arrangement (i.e., structuring) for cooperative and efficient decision-making. In sum, decision-making in teams/groups is an interdependent process that is substantially affected by the available information, the requirements for completing a task, and the feedback of other team members.

Vogus and Sutcliffe (2007) defined HROs as "organizations that operate hazardous technologies in a nearly error-free manner under trying conditions rife with complexity, interdependence, and time pressure" (p. 2). Typical examples of HROs include emergency rescue crews, such as fire brigades, and aircraft or spacecraft crews. We similarly define High Reliability Teams (HRTs) as "any set of two or more team members who consistently and effectively work interdependently towards a shared goal in a complex environment" (Wilson et al. 2005, p. 304). Research has demonstrated that organizational reliability supported at the team level result in higher reliability at the organizational level. The extant field research underlines the key role that expertise, pattern recognition, and intuitive decision-making play in safety performance in HRTs (Okoli et al. 2016). Their use of technology obviously also has an impact. However, the role of Information Technologies (IT) in supporting decision-making processes has mostly been studied in "cold" contexts, that is, during the planning and briefing tasks that precede an intervention.

Decision Support Systems (DSSs) and Group Decision Support Systems (GDSSs) have also played important roles in supporting strategic decision-making processes 
(Keen 1980; Ter Mors et al. 2005). Specifically, GDSSs have been used in a gaming simulation environment to support modern emergency planning and management (Beroggi et al. 2001; Mendonça et al. 2006; Yu and Lai 2011). GDSSs have been mindfully designed as a form of technological support that tightens tasks and microprocesses, which in turn helps improve decision-making and reduce both individual biases and collective biases such as groupthink (Janis 1982).

GDSS scholars have been pioneers in addressing both the human and material agencies at the operational and strategic decision-making level of groups in organizations. Although different ontological approaches underpinned the development of major GDSSs (Ackermann and Eden 2001; Briggs et al. 2003), researchers in the field nevertheless provided essential steps for understanding what Orlikowski (2007) later defined as sociomateriality. Sociomateriality is "the recursive intertwining of humans and technology in practice" (Orlikowski 2007, p. 1437). We define material agency as the agency expressed by nonhuman entities (Jones 2014) and human agency as the capacity for human beings to make decisions (Bandura 1989). Majchrzak and Markus (2012) suggest considering the interactions between material agency and human agency simultaneously, rather than focusing on technological features or human attributes separately, for affording (i.e., enacting) or hindering, for example, collaboration. From that perspective, affordances and constraints emerge when users engage with technology. Affordance refers to an "action potential", that is, what a user can do with a technology for a particular purpose (Markus and Silver 2008). Constraints concern the ways in which technology may limit users or an organization. Affordances are by definition sociomaterial (Leonardi and Barley 2008; Van Osch and Mendelson 2011). Further research introduced a differentiation among individual, collective, and shared affordances when considering the use of technology at the group level (Leonardi 2013a). In the context of GDSSs, the material agency may not afford (enact), for instance, knowledge sharing or brainstorming and therefore bias part of the decision-making process. The GDSS literature views technologies as enablers of efficient decision-making and effective strategies in distributed and face-to-face context (Ackermann 1996). The imbrication of human and material agencies has afforded a sharper definition of problems through distributed and pooled output and the efficient categorization of information and reduced funnel vision overall.

GDSSs are not merely a software product provided to users, but represent the very first imbrication of human agency (i.e., participants, chauffeur, or facilitator) and material agency in the form of software tools (i.e., Decision Explorer, Group Explorer, Group Support System, Strategic Options Development, and Analysis). The goal is to achieve efficient decision-making in practice. The combination between task complexity and interdependence has been an important part of the analyses in the G(D)SS literature. It relates to both the processes and outcomes of task performance.

Complexity plays a key role in differentiating task environments (Campbell 1988), In this paper, we define task complexity as "the amount of processing or attention required by a task, or the amount of structure or clarity provided by a task" (Bonner and Sprinkle 2002, p. 319) with the complexity of a task depending on at least four elements: outcome multiplicity, solution scheme multiplicity, conflicting interdependence, and solution scheme/outcome uncertainty (Luo et al. 2011; Wood 1986; Zigurs and Buckland 1998). Prior research in the GDSS field has demonstrated the 
importance for effective performance of the fit between the task and the technology (Zigurs and Buckland 1998). In addition, scholars have directly mapped the level of collaborative capabilities influenced by a form of "intellectual bandwidth" fitting to the organizational tasks (Nunamaker Jr. et al. 2002). In Asch's (1952) terms, researchers closely considered the impact of technological design in affording decision-making as the arrangements and structuration, rather than the simple aggregation, of human information processing. In teams, the complexity and uncertainty of task performance increases (De Dreu and Weingart 2003; McGrath 1984). Congruently, technology usage affords decision-making differently at the team level.

In the recent past, HROs have implemented off-the-shelf technologies such as smartphones to help team members cope with "hot" situations. For instance, in the context of emergency response on the part of firefighting brigades, smartphone applications with embedded collaborative features have been demonstrated successful in supplying role-specific information independent of time and place that affords collaboration (Rossel et al. 2016). The decision-making has thus become more efficient in such contexts. The use of mobile technology during special missions or critical processes may increase the level of elasticity required in HROs when dealing with extreme uncertainty (Van Fenema 2005). Indeed, when fuzzy tasks are being executed, material agency provides high levels of communication support and information processing that is complemented by human process structuring (Zigurs and Buckland 1998). In sum, smartphone technologies can enable greater coherence and order and better interpersonal communications, all of which are essential in such "hot" situations.

Technology usage, however, can also make tasks more complex. While technologies are often developed to reduce task complexity, we emphasize that technologies can afford or constrain human decision-making, and therefore micro-processes: if the imbrication between the material and human agencies is not taken into account. The use of smartphone technology by police forces provides an interesting example, which will be studied in detail in this paper. Technology is highly interwoven into the daily practice of police work (Manning 2008; Sørensen and Pica 2005). The "smartphone on the street" has surely modified the landscape of decision-making in police forces. For example, a failure to enact technological affordances introduces potential risks for such an organization. Also, police officers have had to work around constraints brought on by technology during critical processes in order to keep their performance stable (Verhulst and Rutkowski 2017).

This article presents the results of a field study that ran from July 2015 to August 2016, shortly after the MEOS was introduced. Specifically, we investigated the extent to which smartphone technologies (MEOS) enables individual, collective, and shared affordances. The "More and Effective on the Street" smartphone (MEOS) is equipped with a range of applications developed within the police force organization. The MEOS smartphone provides the same functionalities as any recent smartphone: camera, email, turn-by-turn navigation, etc. Additionally, using a specific application, police officers are able to access the police information systems (e.g. look up license plate information, personal information) or issue a fine. The device provides the functionalities required to conduct simple, problem-solving, decision, judgement as well as fuzzy tasks supporting police officers in completing their administrative work independently of time and place. 
Police officers were shadowed for a period of 80 hours. Notes regarding incidents, work practices, and the use of the technologies served as material for the analysis. Police work is centered on incidents. Incidents are defined as a specific event where the police responses are required to ensure law and order. Incidents range from the arrest of a shoplifter, to armed robbery or burglary to name only a few. The data were alternately collected from two precincts for accuracy. We used a three-step approach. First, we built on the work of Zigurs and Buckland (1998) to assess the fit between material agency (i.e., the technology used in the police force) and the tasks performed by the officers (i.e., human agency). Second, we built on the work of McGrath (1984) in order to provide a greater understanding of the tasks and micro-processes at the team level. Third, we composed narrative vignettes based directly on field notes collected during the observation stage to illustrate the impact of the imbrication of material and human agencies on individualized, collective, and shared affordances in practice.

This paper is organized as follows. The theoretical section provides an overview of decision-making and task performance in the Dutch National Police Force. We also discuss sociomateriality and the concept of affordance in that section. The next section presents the research methods used for the field study and analyzing the observations. The results are then presented, and we conclude by discussing the study's limitations and ideas for future research.

\section{Theoretical Background}

\subsection{Task-Technology Fit and Decision-Making in High Reliability Teams (HRTs)}

In their seminal work on task-technology fit, Zigurs and Buckland (1998) synthesized the literature on task. Task complexity depends on four factors: outcome multiplicity (i.e., more than one desired outcome), solution scheme multiplicity, conflicting interdependence (i.e., adopting one scheme conflicts with adopting another possible solution scheme), and solution scheme/outcome uncertainty (Luo et al. 2011; Zigurs and Buckland 1998). The authors also identified five task categories: simple tasks, problem tasks, decision tasks, judgement tasks, and fuzzy tasks. Simple tasks do not entail any outcome multiplicity (i.e., there is only one possible outcome), solution scheme multiplicity, or conflicting interdependence. The main goal of a collaborative technology in supporting simple tasks is communication support. Problem tasks are aimed at finding the best solution scheme among multiple possibilities. The goal of the collaborative technology for problem tasks is information processing. Decision tasks have no solution scheme multiplicity, but they vary in outcome multiplicity. In addition, for every possible outcome, a different stream of information may be needed, requiring high information diversity and information load. Here, the technology should satisfy both information and process-structuring needs. Judgement tasks are characterized by the focus on resolving conflicts and uncertainty in terms of information. To resolve conflicts, the technology should mainly provide communication support and information processing functionalities. Finally, fuzzy tasks have a high outcome multiplicity and high solution scheme multiplicity. The technology 
should provide high levels of communication support and information processing, complemented with a medium level of process structuring (Zigurs and Buckland 1998).

While it is a challenge to come up with an unequivocal definition of what the essential task of a police force is, it is not a stretch to assume that police officers deal with far more than simple tasks primarily. For instance, even when issuing a basic parking ticket, the outcome can be unpredictable and lead to the use of force. To sum it up in a nutshell, the tasks of the police force are "grounded in a roundthe-clock capacity to take decisive action in handling all kinds of emergencies and to employ force where it is needed" (Smith et al. 1996). Police intervention is time critical, encompassing outcome multiplicity, solution scheme multiplicity, conflicting interdependence, and solution scheme/outcome uncertainty. Officers use various strategies to cope with uncertainty and must therefore handle fuzzy tasks. They may extrapolate future scenarios based on the information available or use assumptionbased reasoning to mentally simulate outcome multiplicity (Van den Heuvel et al. 2014). Experienced police officers outperform their less experienced counterparts in their assessment of environments with multiple cues (Garcia-Retamero and Dhami 2011). Such behavior is often exhibited by members of HRTs who tend to follow their "gut feelings" in "hot" situations. One example might be when they decide there is no "exit option" and the decision taken must be followed through on-this is the case even when the use of deadly force is required. The significant consequences of failure, unpredictability, and time pressure in a police force are the three main characteristics of the HRO environment. Police officers must consequently make informed choices between discretionary decisions and procedures. Work rules and procedures (i.e., heuristics) develop among the officers over time, which are then implicitly or explicitly used to decrease the cognitive burden of discretionary decision-making (Stroshine et al. 2008). Moreover, contextual cues allow officers to assess whether certain behaviors are "suspicious" and to predict potential outcomes (Stroshine et al. 2008). When on duty, police officers are regularly confronted with non-cooperative civilians or suspects. As a result, they must routinely engage in emotional labor (Van Gelderen et al. 2011). According to the work of Scharf and Binder (1984), the police decision-making process can be broken down into four stages: anticipation, entry and initial contact, dialogue, and information exchange (Scharf and Binder 1984). The four steps are required for reaching a final decision. During the anticipation phase, the officers retrieve and look-up information, which is then confirmed or rejected during the contact phase. Congruently, informational cues relating to a suspect may significantly impact the decision to use deadly force during a face-to-face confrontation (Fridell and Binder 1992).

Police officers commonly operate in dyads, and when they respond to incidents, they frequently also interact with other dyads. McGrath's (1984) circumplex has been used as a proxy to identify the complexity and uncertainty of performance tasks in teams (De Dreu and Weingart 2003). Prior literature has focused on planning-production tasks, decision-making, and project tasks (De Dreu and Weingart 2003). In their categorization, De Dreu and Weingart (2003) view planning-production tasks in terms of routines because these tasks incorporate low levels of uncertainty and complexity. The degree to which team members need to interact with and rely on other team 
members for information and resources is defined as task interdependence (Kiggundu 1981). Task interdependence can be categorized as pooled, sequential, reciprocal, or comprehensive (Saavedra et al. 1993). As discussed previously, this is key to understanding the role of technology in police work. Decision-making tasks in HRTs are marred by high levels of uncertainty and complexity because the tasks require consensual decisions among team members. As a result, decision-making in this context becomes a challenge. Tasks that need both planning and decision-making are considered to be highly complex and non-routine (De Dreu and Weingart 2003). Prior literature has thus used McGrath's (1984) circumplex to examine group tasks as a way of disentangling these tightly coupled, complex processes. It has been used to study and classify the tasks to be completed by diverse teams in different settings. Medina et al. (2015), for example, built on this theoretical perspective to understand the use of Information Technology (IT) for assuming tasks (i.e., work substitution) in the operating room.

The circumplex is divided into four quadrants: generate, choose, negotiate, and execute. The four quadrants are then divided into two segments per quadrant. Each is a representation of a micro-process. The first quadrant, generate, consists of planning and creativity tasks. The Planning (1) segment refers to how a specific plan or action needs to be carried out. Creativity (2) refers to coming up with new ideas. The second quadrant, choose, consists of intellective tasks and decision-making tasks. Intellective tasks (3) refer to solving a problem that has one correct answer. Decisionmaking tasks (4) cover the type of tasks for which there is no one correct answer. The third quadrant, negotiate, entails Cognitive conflict tasks (5), which are aimed at resolving conflicts of viewpoint, and Mixed-motive tasks (6), which have to do with situations where motives differ among those involved but an agreement needs to be reached. The fourth and final quadrant, execute, covers contests and battles and performances/psychomotor tasks. Contests and battles (7) involve resolving conflicts of power, where there is only one clear winner (among the team members). The last segment, Performances/psychomotor tasks (8) covers physical tasks. The circumplex is of a continuous nature, such that each category is linked to its adjacent categories - but not necessarily interdependent. In addition, the circumplex is cyclical in nature. Planning tasks are followed by creativity, then intellective tasks, and finally at the end, the circle is completed by the psychomotor/performance tasks (McGrath 1984). At the team level, decision-making (Types 3 and 4) relates to decision tasks that vary in outcome multiplicity but not in solution scheme multiplicity. Judgement tasks are characterized by the focus on resolving conflicts (Types 5 and 6) and uncertainty in terms of information; they can be compared to fuzzy tasks.

The model encompasses tasks in a broad sense to investigate the impact of technologies during decision-making activities. Rees and Barkhi (2001) lament the discrepancy of the category of GDSS tested in experiential settings (mainly idea generation, Type 2 ) and the practical applications of GDSS that revolve around constrained production and budget planning tasks (solving problems with correct answers, Type 3) and planning tasks (Type 1). We propose combining both task-technology fit and the McGrath circumplex in order to build an efficient theoretical framework for uncovering the imbrication between human and material agencies in HRTs. 


\subsection{Sociomaterial Imbrication and Affordances}

A debate surrounding the exact interpretation of sociomateriality is waging in the Management Information Systems (MIS) literature (Kautz and Jensen 2012; Leonardi 2012; Niemimaa 2016; Scott and Orlikowski 2013).

Based on the earlier work of Zigurs and Buckland (1998), we assume that the human and material can be separated as they are in the context of task complexity and are thus imbricated in practice. Thus, we follow the school of thought of Leonardi and others that view sociomateriality through a critical realism philosophical lens (Leonardi 2012, 2013b; Leonardi and Barley 2008). The social and material agencies are not entangled (Orlikowski 2007; Orlikowski and Scott 2008; Scott and Orlikowski 2012), but imbricated in practice. Imbrication implies an interlocking of social and material agency, allowing for a distinction to be drawn where material agency ends and human agency begins. Recent work has aimed to integrate the two streams of sociomateriality literature. Kautz and Jensen (2013) point out that the main difference between them is the choice of vocabulary when referring to the social and the material being imbricated in practice (Leonardi 2012) or the human and the technology being entangled in practice (Orlikowski 2007). Leonardi (2011) suggests that "people's work is not determined by the technologies they employ" (p. 148). In other words, users are free to decide how they use a certain technology, assessing mindfully how it might better serve their task or team interest in reaching their goal. When humans experience constraints from technology, they can change it. Conversely, the feeling of affordance causes them to change their own routines. Leonardi (2011) examined the effects of the imbrication between human and material agency on work routines. He argues that the interplay between material and human agency develops over multiple iterations and that the perception by humans of technology constraining their behavior leads them to modify their technology usage. On the other hand, if the technology results in humans perceiving affordance, this affects their routines through imbrication (Leonardi 2011).

Prior research has not addressed human and material agencies at the team level in the context of decision-making. However, Leonardi (2013a) studied how affordances were used within and between groups in accomplishing organizational network change. We define individualized affordance as a specific instance "that someone enacts when using a technology's features, but that affordance is not common to his or her workgroup or department" (Leonardi 2013a, p. 752). A shared affordance is defined as "an affordance that is shared by all members of a group" (Leonardi 2013a, p. 752). Lastly, a collective affordance is defined as "an affordance that is collectively created by members of a group, in the aggregate, which allows the group to do something that it could not otherwise accomplish" (Leonardi 2013a, p. 752). The differentiation between individualized, shared, and collective affordances relies on task interdependence (Leonardi 2013a). However, Leonardi does not take into account the wide variety in levels of interdependence and their potential effects on the level of affordance at the team level. As Saavedra et al. (1993) argue, different levels of interdependence exist, and these are especially relevant within the context of HROs such as the police force. Task interdependence is deemed to be pooled, sequential, reciprocal, or comprehensive (Saavedra et al. 1993). Pooled interdependence is observed when group members complete their task independently, and the outcome is simply combined to represent 
the team output. Sequential interdependence is when team members perform different tasks in prescribed sequence, and team members only depend on the output previously provided in the sequence. Reciprocal interdependence is when team members interact with only a limited subset of other team members to complete the team's work. Comprehensive interdependence is when team members have a great deal of discretion in terms of what they do and with whom they interact in the course of the collaboration involved in accomplishing the team's work (Saavedra et al. 1993).

The use of mobile technology during critical processes may increase the level of elasticity required in HRTs when dealing with extreme uncertainty (Van Fenema 2005). Based on the discussion above, we assume that the degree of elasticity can be observed in practice through individual, collective, and shared affordance. The distinction between individualized, collective, and shared affordances is essential in studying collaborative technology, since the level of affordance is reflected in the level of decision-making. Individual decision-making may require only individualized affordance. Yet, when multiple team members are involved in the process, in situations of high interdependence and uncertainty, collective or shared affordance should emerge. This relationship between the level of affordance and the level of decision-making is two-fold. First, there may be a direct relationship between decision-making and the level of affordance; that is, individual decision-making implies an individualized affordance of retrieving information to reduce uncertainty. In group decision-making, collective affordance emerges, where the ability for the team to achieve a goal is a sum of the individual affordances. Second, collaborative communication technologies' affordance affects the level of decision-making. A shared affordance enables shared decision-making in cases where synchronous communication is required for decisionmaking. In addition, collective affordances may enable shared decision-making in the case of pooled interdependence in the decision-making task. For example, each of the group members may supply different pieces of the information required for the group to make its decision. In this explorative field study, we address the impact on individual, collective, and shared affordances of mobile technology (i.e., smartphone) as employed in the daily work routine of police officers on the streets.

\section{Explorative Field Study}

\subsection{Research Method}

Throughout 2016, following the introduction of the MEOS, 10 teams of two police officers each were shadowed during their daily work for a period of 80 hours at two police stations in the Netherlands. To ensure a diversified impression of the police work, the times of observation varied: two day shifts (7 a.m. until roughly 4 p.m.); eight afternoon shifts (2 p.m. until roughly 10 p.m.); and one night shift (8 p.m. until roughly 5 a.m.). The data was collected over a period of 10 months. A total of 34 incident responses were identified following the structuration of the observation. Typically, when the team of police officers was not involved in an incident, they would spend time patrolling or conducting smaller police tasks, such as handing out court summons or completing administrative work at the police station. 
It was agreed with the police organization that video recording equipment would not be used, so as to avoid any legal implications for the police, victims, suspects, and other stakeholders. In order to ensure privacy, a non-disclosure agreement was signed. Full disclosure regarding the purpose of the research was given to the police officers. Officers were encouraged to engage in the study and share their rich experiences on the use of technology in practice. During the observations, no details regarding suspects or victims were recorded. The recorded data were anonymized and shared with the organization after analysis. Observations on any kind of impressions regarding what was witnessed were recorded directly, rather than deciding in advance which elements were relevant for the data collection (Eisenhardt 1989). Data were collected using electronic media and paper. Within 24 hours, additional information was added to the field notes and structured. Secondary data were composed of notes taken during weekly meetings of the Business Support unit of the Dutch National Police's organizational program responsible for development and implementation of the smartphone within the department. Additionally, internal documents such as the business case for the implementation of the smartphone and the implementation plan were analyzed. The police organization defines mobile technologies as the technologies that can be used irrespective of time and place. We limited our research to the technologies carried by the officers on their person, excluding the mobile and other technology in police vehicles and at police stations.

\subsubsection{Data Analysis}

The 34 incidents were used to structure the observations. To identify the variety of affordances that emerged, we modeled our approach after Pentland and Rueter (1994), looking at routines as a grammar of action in the context of help desk employees. We focused on the narrative as well as the collected feedback, making sense of the events from an incident collaborative perspective. Service calls and police incident responses revolve around solving a problem. In both contexts, the problem is solved by employing previously successful subroutines and procedures to come up with new ways of solving the problem in question.

In the present research, the incident response was "cut up" into smaller subroutines. Each included only one technology being used during that subroutine. This analysis allowed us to identify both similarities and differences between the incident responses. The affordances were coded following a two-stage coding process. First, the technological features in use for each of the subroutines and affordances were identified. Second, we categorized individualized, collective, or shared affordances. Individualized affordances are specifically those that are not shared with other members. Collective affordances are those where one member of the group enacts the technology in a way that benefits the entire team. Shared affordances are present when all of the HRT's members enact the technology in one particular way. Contrary to Pentland and Rueter (1994), we used a narrative approach rather than a statistical descriptive approach. Such an approach has already proven successful for studying the impact of technology on decision-making at the HRT level both in a police force context (Verhulst and Rutkowski 2017) and at the individual level in the context of the operating room of a hospital (Medina et al. 2015). Using such an approach allows us to 
demonstrate the critical impact of mindfulness expressed through the human agency of users/police officers on successful collaboration when using IT in the context of a police organization.

\subsubsection{Vignettes to Explore Narrative}

The use of narrative vignettes in the literature on group decision-making to identify micro-processes was exemplified by Burger et al. (2018). They used a vignette to illustrate the micro-processes at play in a group decision workshop. Exploration narratives with the support of vignettes make it easier to ask participants about their opinions on sensitive topics and also to uncover the judgements individuals may hold in a specific situation (Barter and Renold 2000). Vignettes are also used in survey research to quantitatively measure respondents' hypothetical actions in the situations outlined (Barter and Renold 2000). Alternatively, narrative vignettes can be used to present the results of a qualitative study, showing the significance of key incidents (Khrushlov and Kroon 2002). They are also used to strengthen the rigor of qualitative research and to "let the facts speak for themselves" (Iacono et al. 2009). Narrative vignettes serve as "a vivid portrayal of the conduct of an event of everyday life, in which the sights and sounds of what was being said and done are described in the natural sequence of their occurrence in real time" (Erickson 1986, pp. 149-150).

The vignettes selected and presented here are grounded in the entirety of the body of data that was collected, in accordance with established practice (Miles and Huberman 1994). They were selected based on their power to explain the daily routines of police work, as well as their representativeness. The organizational practice of enforcing the law is an essential part of the police work. Therefore, recurrent incidents related to the previous were reported. Similarly, the other affordances presented in the vignettes were observed multiple times during incident responses. These affordances are the building blocks composing police force's incident responses. The four vignettes have the merit to illustrate how each of the three affordances were typically witnessed in practice. Therefore, these were selected. The affordances identified are a critical part of the daily routines of police officers. The first vignette demonstrates how technology is used in one of the primal tasks of police work: issuing a fine. Vignettes two, three, and four show the centrality of the incident response and the affordances resulting from the use of technology during these responses.

Material Agency As explained in the theoretical section, we build on the work of Zigurs and Buckland (1998) on the task-technology fit approach to assess the fit between material agency (i.e., the technology used in the police force) and the tasks performed by the officers (i.e., human agency). Table 1 provides a detailed analysis of the technologies used in practice by the police force. In the first step, it was possible to map the technology to a particular task and the micro-processes supported.

Table 1 suggests that the technologies used by police officers on the street mostly support simple, problem, and decision tasks. In this article, we focus on the MEOS interface, which is connected to 18 different information systems. The MEOS application offers a variety of functionalities. For example, the Mobile-ID application allows police officers to verify a person's identity based on one single legal docu- 


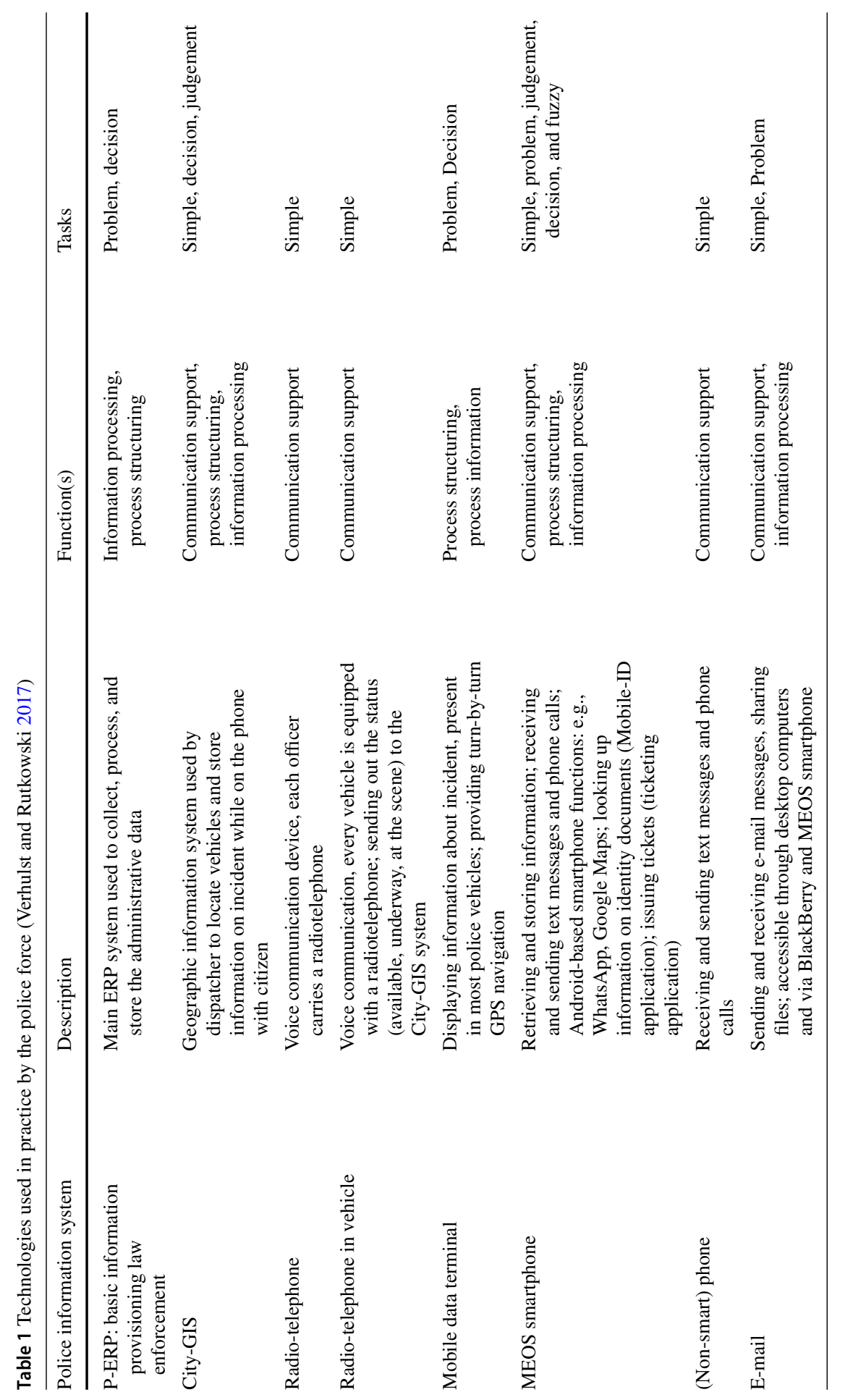


ment: scanning the document and/or reading the information stored in its chip (e.g., passports) provides identification. The Mobile-ID application incorporates a feature that alerts officers when they have encountered a dangerous person by vibrating for a number of seconds. Another functionality allows them to retrieve additional information (e.g., vehicle license and address). Affordances from the applications can be combined for pooling information. For example, the ticketing application can be connected to the Mobile-ID application. The ticketing application allows police officers to search through the applicable sections of law for the appropriate sanction when a fine needs to be issued. Two main categories of information are stored in two different, interconnected systems: governmental and specific police information systems. Non-police information systems contain information such as residence address or vehicle ownership information. Police information systems contain information regarding previous allegations or convictions and a risk categorization (e.g., possession of a firearm, use of drugs/alcohol, mental illnesses). In the process of retrieving the information about an individual, a vehicle, or an address, the technology enables officers to check a person's identity and develop a more complete image of that person. In other words, the information adds to the contextual cues usually used in assessing a suspect's behavior (Stroshine et al. 2008). Along with the specific police functionalities developed in-house, the smartphones provide a range of off-the-shelf functionalities. One of the most frequently used is the camera. Officers use this functionality to not only take pictures of evidence, but also record personal details about a suspect by photographing their identity card. Finally, the officers use the e-mail functionality to take notes by sending an e-mail to their own e-mail address.

Human Agency The officers work primarily in teams of two, coordinating with other HRTs and the dispatcher on a regular basis throughout their shift. A predominance of surveillance and emergency response to incidents was observed and reported as fragments of the field notes: narrative vignettes (Erickson 1986). Incidents are generally called in by a citizen, with the citizen speaking to a dispatcher who then assigns one or multiple HRTs. The officers spend their time otherwise surveilling an area. At the beginning of a shift, the ranking officer shares information with them face-to-face. Topics discussed include significant events that happened during the past 24 hours, felons wanted in the area, and special assignments based on the time of year (e.g., in autumn the risk of burglary might be higher because the days are shorter). The slides used during the briefing are later accessible on officers' smartphones. Officers patrol a given geographical area. The patrols will head to a given location and are in charge of determining an appropriate response when assigned to an incident. In the context of this study, we defined HRTs responding to an incident as a "focal group". Police officers develop routines using their own discretion (Stroshine et al. 2008). We build on the work of McGrath (1984) to provide a greater understanding of tasks at the team level. In Table 2, we illustrate each of the segments from the McGrath circumplex with an example specific to the police micro-processes observed in practice. 
Table 2 Illustration of micro-processes in the police force

\begin{tabular}{|c|c|c|}
\hline Quadrant & Segment & Micro-process example \\
\hline \multirow[t]{2}{*}{ I. Generate } & 1. Planning: generating plans & Developing a plan on how to locate a suspect \\
\hline & 2. Creativity: generating ideas & $\begin{array}{l}\text { Coming up with ideas on how to catch up with a } \\
\text { car driver who has fled the scene of an accident }\end{array}$ \\
\hline \multirow[t]{2}{*}{ II. Choose } & $\begin{array}{l}\text { 3. Intellective: one specific } \\
\text { correct answer }\end{array}$ & Determining the identity of a citizen \\
\hline & $\begin{array}{l}\text { 4. Decision-making: preferred } \\
\text { answer is the correct answer }\end{array}$ & $\begin{array}{l}\text { Coordinating with team members on the } \\
\text { preferred approach to catch teenagers seen } \\
\text { with guns }\end{array}$ \\
\hline \multirow[t]{2}{*}{ III. Negotiate } & $\begin{array}{l}\text { 5. Cognitive-conflict tasks: } \\
\text { Resolving conflicts of } \\
\text { viewpoint }\end{array}$ & $\begin{array}{l}\text { Establishing consensus with fellow officers on } \\
\text { how facts should be categorized in the system } \\
\text { as a function of the offense }\end{array}$ \\
\hline & $\begin{array}{l}\text { 6. Mixed-motive tasks: } \\
\text { Resolving conflicts of interest }\end{array}$ & $\begin{array}{l}\text { Bargaining with a suspect (e.g., when he } \\
\text { cooperates and behaves no handcuffs will be } \\
\text { used) }\end{array}$ \\
\hline \multirow[t]{2}{*}{ IV. Execute } & $\begin{array}{l}\text { 7. Contests/battles: resolving } \\
\text { conflicts of power }\end{array}$ & $\begin{array}{l}\text { Trying to outsmart a driver who has illegally fled } \\
\text { the scene of an accident he is involved in }\end{array}$ \\
\hline & $\begin{array}{l}\text { 8. Performances: physical } \\
\text { activities and execution tasks }\end{array}$ & Writing a ticket for a car parked on the pavement \\
\hline
\end{tabular}

\section{Analysis and Discussion}

\section{Vignette 1: Individual Affordance: Enforcing the Law}

During their surveillance, the police officers spot a car illegally parked on the pavement. After some deliberation, they decide that they will issue a ticket. The officers calmly exit their vehicle, and one of them takes out her smartphone and opens up the dedicated application to complete this task. She enters all the required information (location, vehicle identification, offence) and attaches a picture of the parked car that will serve as evidence.

The first narrative vignette represents how technology is being used to enforce the law. Once the information has been entered into the system, the citizen will receive a fine in mail, and he/she will need to pay the ticket or face additional charges. Such a micro-process does not require collaborative activity. It is a simple task requiring that the officer make a decision with a right answer (McGrath 3) on what they have witnessed, combining that with the laws that apply. The affordance of enforcing the law through the MEOS smartphone is categorized as a McGrath 8, since it is considered to be the execution of police work. 


\section{Vignette 2. Three Collective and Shared Affordances: Weapon Seen with Teenagers}

So far, it has been a quiet night for the two officers on patrol at the fancy fair. Around 12 a.m., though, a radio call comes in from the dispatcher that a group of youngsters has been spotted on the security cameras. One of them appears to be carrying a firearm. Two teams of officers are directed to the location where the group was spotted. Using their radiotelephones, the officers communicate quickly about the estimated time of arrival at destination. The officers all approach cautiously from different directions. They seem fully concentrated on the task at hand. The suspect is identified based on the information provided by their colleagues, derived from the security cameras, and received from the dispatcher. From that moment, the police response shifts into an even higher gear. Two officers separate the suspect from the group. He is pressed firmly against a nearby glass wall. He is searched, and the suspicious object, a plastic replica of a gun, is found. Once it becomes clear that there is no actual weapon involved in this situation, the atmosphere becomes less tense. The bags and pockets of the other youngsters are also searched. Because carrying any object that resembles a firearm is forbidden under certain circumstances, the incident has to be reported. Using the smartphone, the officers retrieve the personal details of the suspect. Since the suspect is a minor, special rules apply. The boy's parents are called and informed that their son will be brought home by the police. Meanwhile, the police officers discuss how to correctly enter the information into the system. More discussions follow regarding the section of law that has been broken. With the information provided by the MEOS ticketing application, the officers reach a consensus.

The second vignette covers three additional affordances: coordinating, understanding the situation, and reaching consensus. The coordinating affordance is categorized as McGrath 1: generating plans. Here, the officers communicate using their radiotelephones to agree on the planning. The second affordance, understanding the situation, involves looking up the information about the suspect using the smartphone; using this information, the officers are able to collectively decide how to proceed. In this specific instance, the fact that the suspect is a minor influences the decision as to whether to take him to the police station or home to his parents instead. The answer agreed upon is regarded as the correct one, thus this affordance is categorized as McGrath 4. The third affordance, reaching consensus, involves a process in which the officers use information retrieved through a smartphone to discuss and reach consensus. In this case, additional information about the legislation on replica firearms that had recently changed was needed to convince all of the officers involved about the course forward and resolve the conflict of viewpoint regarding the situation.

\section{Vignette 3: One Collective Affordance: Verification of Identity}

A report comes in via the radiotelephone. Five teenagers have been spotted in a local parking garage carrying bags. It is unclear what the purpose of their presence is. Two teams of two officers head out to the parking garage; they are eager to catch the suspects. The teenagers are found and brought outside. Because they have no explanation for their presence, the officers use Mobile-ID to check the teenagers. Upon consulting the system, it becomes clear that one of the teenagers is housebound 
to a juvenile home. The officers address the teenager with a stern voice, informing him that he is under arrest. The teenager is taken under arrest, and two officers bring him back to the juvenile home. The remaining youngsters are sent away. A report is filed in the system, registering their unauthorized presence in the parking garage.

In this third vignette, one affordance is identified: verifying. The MEOS smartphone allows the officers to verify the identity of the persons that have been detained. Usually, there is a picture on file that enables the officers to cross-check the picture on the identity card with the picture stored in the system, guaranteeing that the identity card is not forged or has not otherwise been tampered with. Clearly, there is one right answer (McGrath 3): whether or not the suspect is indeed the person he claims to be/represented on the identity card. In this vignette, the MEOS provides the officers with information indicating that one of the suspects resides in a closed facility and does not have the right to be outside unsupervised.

\section{Vignette 4: One Individualized Affordance: Arrest of High-Profile Suspect}

During the past week, a rip deal (drug deal gone awry) has taken place. One of the duped parties has threatened to take revenge at the local fancy fair. This is a serious threat with potentially severe consequences for the safety of everyone present. A warrant for the arrest of the potential victim has also been issued. This information is provided during the pre-shift briefing. Throughout the shift, the officers call up the information from the briefing multiple times, indicating that they are on the alert for any of the parties involved. Later that evening, around 7:30 p.m., two other officers report that they have found the car of the potential target for revenge inside a parking garage near the fancy fair. The hood of the car is still warm, indicating that it has just been parked. This could be an indicator that the wanted person is currently at the fancy fair. After deliberation, officers are posted at numerous central positions in an attempt to locate the suspect. When a suspect is spotted, the officers compare his appearance to the picture presented at the briefing by accessing their smartphones. Although the suspect looks slightly different, the three officers have enough confidence that it is him and approach him. They inform the suspect that they have a warrant for his arrest. Since he is with his wife and children, they agree not to handcuff him if he cooperates.

In the fourth narrative vignette, officers have to make a decision with a right answer about whether a person spotted is the person they are looking for. This demonstrates the affordance of identifying. Making this decision is challenging, since the available photograph may be outdated, and both a false positive and a false negative could have severe consequences for the "suspect". Using the photographs available on their smartphones, the officers reach sufficient confidence that the person they have spotted is indeed the suspect. This affordance is categorized as a McGrath Type 3 task, since there is one right answer to the question of "Is this the person that is wanted?". Table 3 presents a summary of work practice, affordance, and interdependence for each of these vignettes.

A graphical representation of the process can be found in Fig. 1. 


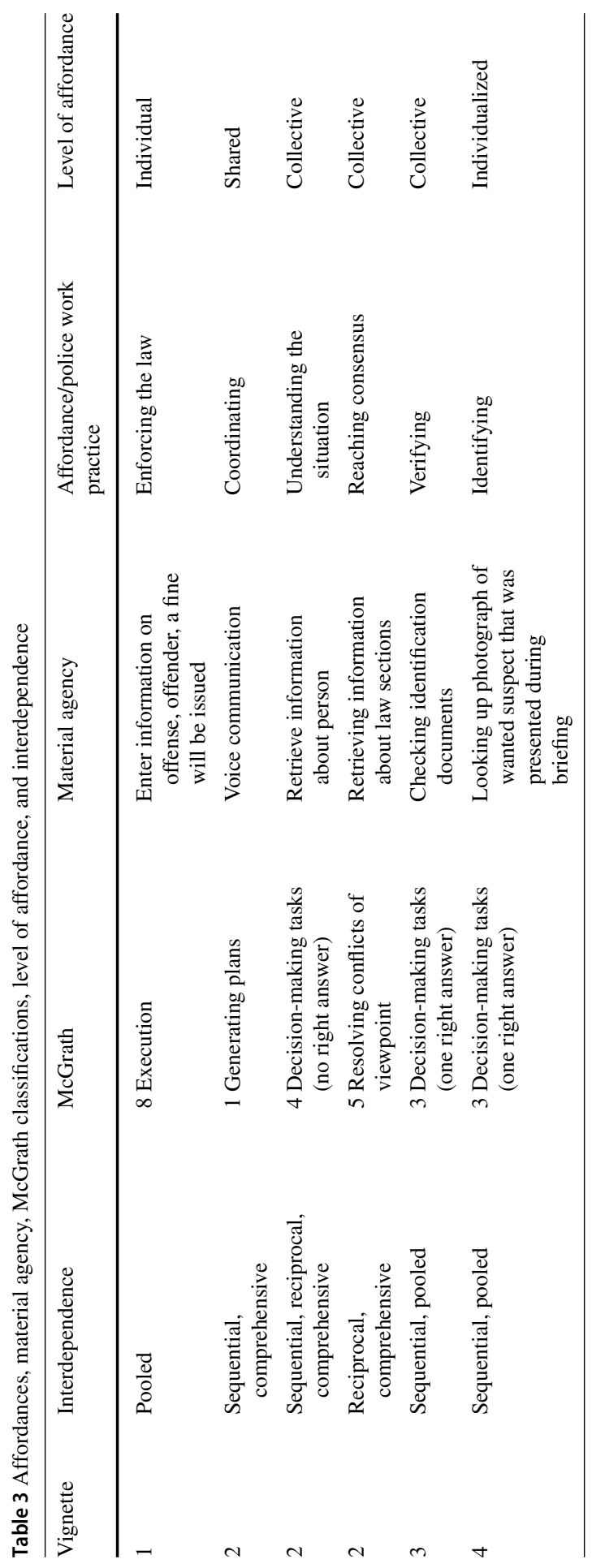






Fig. 1 Conceptual representation of the research

\subsection{Individualized Affordances}

A number of individualized affordances were identified for problem-solving problems with one correct answer. One task frequently conducted by the officers is verifying identity. The Mobile-ID functionality affords the ability to scan a person's identity card, whereupon the officer is presented with supplemental information about the document and the person in question. This allows the officer to make sure that the person is indeed who she/he claims to be. Another affordance in Type 3 tasks is the temporary storage of personal details by taking a picture of an identity card or passport. This allows the officer to look back at this information later, with such details as name and date of birth, thereby limiting the probability of making mistakes. Before the smartphones were introduced, officers would record personal details on a piece of paper, increasing the chance of mistakes. In the individualized affordances discussed here, the task interdependence is sequential. Towards the end of the response to the incident, the tasks are combined, so the interdependence is pooled. Strictly speaking, the individualized affordances could differ between the officers without affecting the outcome at the group level. However, there is a need for standardization, since the information stored is later used by other (external) stakeholders, such as the Department of Justice. Interestingly, although the affordance of issuing a ticket can be considered individualized, the organization can only reach its goal of enforcing the law if a "critical mass" of officers share this affordance. Otherwise, citizens might realize that very few officers were issuing tickets and commit more offences.

\subsection{Collective Affordances}

Collective affordances were witnessed in decision-making that had no right answers (Type 4). Usually, these involved multiple HRTs of officers due to the more complex nature of the situation and hence the decision-making tasks. One of the officers looks up information through the Mobile-ID application, and this information is then shared with colleagues. The information is an input in the further collective decision-making 
process. A similar approach is taken to resolving conflicts of viewpoint during cognitive conflict tasks (Type 5). Information from the ticket application is used as input to discuss and then correctly enter into the system what has happened with a group of youngsters seen with a fake weapon. Also, in a contest to outsmart the suspect who has left the scene of a car accident, one officer looks up additional information on the vehicle's registration. Again, this information is shared with his colleague. The observations on collective affordances align with the pooled and comprehensive interdependence of the tasks that the group has to fulfil, such as in the situation where the youngsters were spotted with a weapon. After the suspects were stopped, different subtasks are divided among the officers: looking up the information or asking questions of the suspect. A decision was made collectively on how to proceed in this situation.

\subsection{Shared Affordances}

Shared affordances were mostly observed during the planning tasks associated with coordination. In our illustration, the officers all share the exact same affordance of using their radiotelephones. In fact, there is a strict policy on the procedures for using the radiotelephones. The policy involves a set of rules on communication procedures. To make certain that every message is received, the dispatcher will first call the designated officer using his call sign (a four-digit number). The officer will then respond, after which the dispatcher passes on the message. The interdependence is therefore sequential. The officer may then request additional information or confirm that the message has been received. If an officer speaks without requesting voice contact first, they will be reprimanded by the dispatcher. The only exceptions to this rule are for emergencies. In their communications using the radiotelephone, there is reciprocal interdependence between the officers. Clearly, even a limited number of officers not enacting the proper use of the radiotelephones could jeopardize the communications (and thus coordination/planning tasks) of all of the officers involved.

In this paper, we assessed how the micro-processes involved in social and material agency result in a range of individualized, collective, and shared affordances. Individualized affordances revolved around officers solving intellective tasks, that is, making sure someone is who he says he is. Yet, in some cases, we saw a similar affordance being used as part of a collective affordance-for example, when one officer looks up information about an address and shares this with his colleagues in the vicinity as input for a discussion on what went down in that situation. The situations in which shared affordance were evident involved planning tasks where officers communicated through their radiotelephone. There is a high level of reciprocal and comprehensive interdependence in such situations. All the officers enacted the affordance of the radiotelephone in a similar fashion. Task interdependence clearly affects the level of affordance. We witnessed an individualized affordance when it came to "identifying" a suspect. In that situation, the officers independently made their assessments as to whether this was the suspect they were looking for. Where one officer used his smartphone to look up a picture, another used a printed picture to identify the suspect. So, although the officers were achieving the same goal (identifying), their affordances were different. We witnessed collective affordances in the cases of decision-making tasks both in 
deciding on a preferred answer (Type 4) and resolving conflicts of viewpoint (Type 5). To reach consensus, one of the officers looked up information and then shared that information with colleagues. The information serves as input in the further collective decision-making process. A similar approach was taken to resolve conflicts of viewpoint during cognitive conflict tasks (Type 5). Information from the ticket application was used as input for discussing and then correctly entering into the system what had happened with a group of youngsters seen with a fake weapon.

This exploratory field study aimed to assess the imbrication in practice between the social and material through the lens of affordances. A number of insights emerge from the illustrations provided. By design, the majority of the smartphone functionalities are intended as individualized affordances. However, in practice, those individualized affordances are enacted as collective or shared affordances as a result of the degree of task interdependence. We observed a shift in terms of technology functionalities as mapped on the McGrath circumplex (McGrath 1984), from micro-processes to microprocesses supporting a particular task. Functionalities that can be categorized as aimed at solving problems with correct answers (Type 3) and functionalities to be used for task execution (Type 8) were both used as inputs in the more complicated decisionmaking tasks for which there is no one correct answer (Type 4). The differentiation between individualized, collective, and shared affordances (Leonardi 2013a) proved useful for studying the impact of technology use on HROs. This study has shown that it is only in practice (Orlikowski 2008) that the enacted can be studied. Indeed, those affordances may differ from those intended by the organizational designers. Clearly, the actualized affordances will push new practices and impact organizational routines (Pozzi et al. 2014).

\section{Conclusion, Limitations, and Future Research}

Our findings may prove useful to practitioners and designers. The results demonstrate the limited predictability of how technology functionalities will be used in practice. From a theoretical perspective, our three-step approach has been useful. The task-technology fit approach certainly proved valuable, since it allowed for micro-processes at the team level to be mapped according to the McGrath approach (1984). Meanwhile, the sociomaterial imbrication lens (Leonardi 2011; Leonardi and Rodriguez-Lluesma 2013; Niemimaa 2016) provided an interesting angle. However, we believe that the entanglement approach (Orlikowski and Scott 2008; Scott and Orlikowski 2014) also has its merits-for example, when the technology becomes an extension of human agency. Requiring as it does time and iteration, we believe entanglement will become more and more evident in the future with the development of new technology such as helmets or technological wearables. Many decisions are being taken even faster and with more connectivity than before. Instead of functioning as a tool in the hands of the worker, technology is developing agency of its own (see Leonardi 2011; Scott and Orlikowski 2012). A "robocop" may not be too far in the distant future, and fiction will become reality.

Every study has its limitations, and here we identify a few of ours. First, we were not able to address the emergence of affordances over time. Similar to other studies 
of this concept (Pozzi et al. 2014), we studied the affordances after emergence. Also, we did not address the circumstances upon which the actualizations of affordances depend. For example, we did not look into the level of tech savviness of the police officers. Interestingly, the anecdotal evidence suggests that the younger police officers seemed more comfortable with the technology. Future studies should therefore closely examine human agency within the law enforcement context, since the decision-making by officers depends heavily on their level of discretion. The greater role played by technologies through their material agency may limit officer discretion (see, e.g., Bovens and Zouridis 2002) and intuition (Dörfler and Ackermann 2012). Due to team DSSs becoming more ubiquitous, users may increasingly rely on those systems instead of their own judgement. Also, it would be interesting to more closely examine the emotional root of officers' decisions and see when and how they take the technological affordances into consideration when deciding to report a fact. Furthermore, it would be interesting to study the diffusion of affordances throughout organizations. The aim of this study was not to report on the 80 hours of observation in a tight case study, but to offer an illustration of the imbrication of human and material agency in practice. Another limitation is that it was not always possible to observe every aspect of the response to an incident at the same time. For example, one cannot simultaneously observe the dispatching police officer, the responding officers, and the citizen reporting the incident. Currently, we are in the process of gathering log data generated by the applications to complement our qualitative approach quantitatively.

To conclude, the implementation of new mobile technologies has surely improved the degree of elasticity and speeded up decision-making processes in HROs (Van Fenema 2005). The availability of such communication support or repositories serves both the synchronous and asynchronous sharing of information. "The availability of such material agency has given opportunities to participate in large-scale sensemaking, problem-solving, and efforts to organize collaborative action" (De Vreede et al. 2016). However, the wild proliferation of technologies in HROs is not trivial. Research has proven that it impacts organizational routines and brings new challenges (Medina et al. 2016; Saunders et al. 2016). Technology is a mixed blessing in achieving reliability in HROs because it increases the amount of information as well as the speed of delivery. While uncertainty is classically associated in the literature with a lack of information (e.g., Daft and Macintosh 1981), an increasing amount of information does not decrease uncertainty systematically. In the context of HROs and IT usage, greater amounts of information may add uncertainty. The volume of solution scheme/outcome uncertainty may simply expand, overloading the decision-makers. It can also interrupt routines that had been efficient in the past. In other words, technology usage may add complexity, increasing equivocality in the decision-making process, even more so when the decision ought to be collective. More research is warranted for considering that crucial dimension. Indeed, in the specific context of HROs, Vogus et al. (2010) have demonstrated that expert individuals have an experientially learned sense of salience that helps them process the incoming information and prioritize their actions. Managing critical incidents requires accurate and minimal processing time (Goldstein and Gigerenzer 2002; Hilbig 2010). Technologies should therefore afford efficient decision-making, not constrain it. While the use of collective intelligence has predominantly been associated with better decisions in times of crisis (Van de 
Walle and Turoff 2008), mostly in terms of reducing information asymmetry, quantity of information is not synonymous with "intelligence". Expertise and dedicated processes are required for organizing the many informational cues at work in order for proper action to be taken towards efficient decision-making. It is therefore dubious to equate better decision-making with the availability of mobile technology in HROs from a linear perspective, especially given that the underlying technological design primarily supports information sharing and barely addresses information processing, other than through automation and algorithms.

Sykes and Macnaghten (2013) stated that "it would be nice to think that (...) we are more capable as a society of considering new technologies in a mature way, and thinking through some of the benefits, and also the potential inequity and downsides, in advance of their application (...) how to ensure the impact of new development creates a better world based on shared values" (pp. 85-86). Two decades ago, Zigurs and Buckland (1998) stated that they "regretted that no generally accepted theory of task-technology fit had emerged yet" (p. 313). In that same period, pioneers in the GDSS field recommended "being cautious of being driven by the opportunities that technological developments provide" (Ackermann and Eden 2001, p. 63). It was after this that Technology, Affordances, and Constraints Theory (TACT) emerged, partly in response to Zigurs and Buckland's (1998) desire for a theory to understand the fit between tasks and technology.

Finally, the benefits of using technologies are clear when addressing collaborative activities in HROs and HRTs, as underlined in this article, as well as in reducing information asymmetry at the societal level in crisis situations (Turoff et al. 2004). However, up until now, too little effort has been focused on the impact of the technological design (material agency) on group processes in practice. Off-the-shelf technologies may be used inconsiderately in organizations. There is a lack of thorough studies addressing the combination between task interdependence and affordances. For example, organizations nowadays apply comprehensive approaches involving collaboration among private and public stakeholders in times of peace or crisis (Gans and Rutkowski 2015). It might be necessary to responsibly design technology that affords collaboration among stakeholders. Based on our work, these shared affordances could be theoretically supported with a tight understanding of the interdependencies to cradle mindful decision-making. Such an approach would also be of added value in addressing new challenges ranging from cybersecurity to cyber defense. Hopefully, our research represents an initial step in proposing a way to tackle these types of problems.

Open Access This article is distributed under the terms of the Creative Commons Attribution 4.0 International License (http://creativecommons.org/licenses/by/4.0/), which permits unrestricted use, distribution, and reproduction in any medium, provided you give appropriate credit to the original author(s) and the source, provide a link to the Creative Commons license, and indicate if changes were made.

\section{References}

Ackermann F (1996) Working with groups using groupware: electronic problem structuring and project management support for face to face and dispersed organisational groups. In: Glasson B, Vogel D, 
Bots P, Nunamaker J (eds) Information systems and technology in the international office of the future. Springer, New York, pp 13-27

Ackermann F, Eden C (2001) Contrasting single user and networked group decision support systems for strategy making. Group Decis Negot 10:47-66. https://doi.org/10.1023/A:1008708912048

Asch SE (1952) Group forces in the modification and distortion of judgments. In: Social psychology. Prentice-Hall, Inc., Englewood Cliffs, NJ, pp 450-501

Bandura A (1989) Human agency in social cognitive theory. Am Psychol 44:1175-1184. https://doi.org/1 0.1037/0003-066X.44.9.1175

Barter C, Renold E (2000) I wanna tell you a story: Exploring the application of vignettes in qualitative research with children and young people. Int J Soc Res Methodol 3:307-323. https://doi.org/10.108 $0 / 13645570050178594$

Beroggi GEG, Van Gent D, Mendonça D, Wallace WA (2001) Assessing group decision support systems for emergency response using gaming simulation. In: International emergency management society conference, Olso, Norway

Bonner SE, Sprinkle GB (2002) The effects of monetary incentives on effort and task performance: theories, evidence, and a framework for research. Acc Organ Soc 27:303-345. https://doi.org/10.1016/S03613682(01)00052-6

Bovens M, Zouridis S (2002) From street-level to system-level bureaucracies: how information and communication technology is transforming administrative discretion and constitutional control. Public Adm Rev 62:174-184. https://doi.org/10.1111/0033-3352.00168

Brehmer B (1992) Dynamic decision making: human control of complex systems. Acta Psychol (Amst) 81:211-241. https://doi.org/10.1016/0001-6918(92)90019-A

Briggs RO, De Vreede G, Nunamaker JF Jr (2003) Collaboration engineering with ThinkLets to pursue sustained success with group support systems. J Manag Inf Syst 19:31-64

Burger K, White L, Yearworth M (2018) Why so serious? Theorising playful model-driven group decision support with situated affectivity. Group Decis Negot. https://doi.org/10.1007/s10726-018-9559-9

Campbell DJ (1988) Task complexity: a review and analysis. Acad Manag Rev 13:40-52. https://doi.org/1 0.5465/AMR.1988.4306775

Daft RL, Macintosh NB (1981) A tentative exploration into the amount and equivocality of information processing in organizational work units. Adm Sci Q 26:207-224. https://doi.org/10.2307/2392469

De Dreu CKW, Weingart LR (2003) Task versus relationship conflict, team performance, and team member satisfaction: a meta-analysis. J Appl Psychol 88:741-749. https://doi.org/10.5465/APBPP.2002.7516 590

De Vreede GJ, Antunes P, Vassileva J, Gerosa MA, Wu K (2016) Collaboration technology in teams and organizations: introduction to the special issue. Inf Syst Front 18:1-6. https://doi.org/10.1007/s1079 6-016-9632-3

Dörfler V, Ackermann F (2012) Understanding intuition: the case for two forms of intuition. Manag Learn 43:545-564. https://doi.org/10.1177/1350507611434686

Eisenhardt KM (1989) Building theories from case study research. Acad Manag Rev 14:532. https://doi.or $\mathrm{g} / 10.2307 / 258557$

Erickson F (1986) Qualitative methods in research on teaching. In: Wittrock MC (ed) Handbook of research on teaching. Macmillan, New York, pp 119-161

Fridell LA, Binder A (1992) Police officer decisionmaking in potentially violent confrontations. J Crim Justice 20:385-399. https://doi.org/10.1016/0047-2352(92)90075-K

Gans B, Rutkowski A-F(2015) Social consciousness in post-conflict reconstruction. In: Kaminski B, Kersten GE, Szapiro T (eds) Proceedings of the 15 th international conference on group decision \& negotiation (GDN 2015). Springer, Heidelberg, pp 31-45

Garcia-Retamero R, Dhami MK (2011) Take-the-best in expert-novice decision strategies for residential burglary. Heuristics Found Adapt Behav 16:163-169. https://doi.org/10.1093/acprof:oso/978019974 4282.003.0030

Goldstein DG, Gigerenzer G (2002) Models of ecological rationality: the recognition heuristic. Psychol Rev 109:75-90. https://doi.org/10.1037/0033-295X.109.1.75

Hilbig BE (2010) Reconsidering "evidence" for fast-and-frugal heuristics. Psychon Bull Rev 17:923-930. https://doi.org/10.3758/PBR.17.6.923

Iacono J, Brown A, Holtham C (2009) Research methods-a case example of participant observation. Electron J Bus Res Methods 7:39-46. https://doi.org/10.1007/s10488-013-0528-y 
Janis IL (1982) Groupthink: psychological studies of policy decisions and fiascoes, 2nd edn. Cengage Learning, Boston

Jones M (2014) A matter of life and death: exploring conceptualizations of sociomateriality in the context of critical care. MIS Q 38:895-925. https://doi.org/10.1080/0144929X.2012.705894

Kautz K, Jensen TB (2012) Debating sociomateriality: entanglements, imbrications, disentangling, and agential cuts. Scand J Inf Syst 24:89-96

Kautz K, Jensen TB (2013) Sociomateriality at the royal court of IS. A Jester's monologue. Inf Organ 23:15-27. https://doi.org/10.1016/j.infoandorg.2013.01.001

Keen PGW (1980) Adaptive design for decision support systems. SIGMIS Database 12:15-25. https://doi. org/10.1145/1017654.1017659

Khrushlov G, Kroon S (eds) (2002) Key incident analysis and international triangulation. In: Teaching mother tongue and Russian in polyethnic schools of the Russian Federation: Cases from the Republic of Altai, the Republic of Bashkortostan and the City of Moscow. INPO, Moscow, pp 5-14

Kiggundu MN (1981) Task interdependence and the theory of job design. Acad Manag Rev 6:499. https:// doi.org/10.2307/257385

Klein G (1999) Sources of Power. MIT Press Ltd, Cambridge

Leonardi PM (2011) When flexible routines meet flexible technologies: affordance, constraint, and the imbrication of human and material agencies. MIS Q 35:147-167

Leonardi PM (2012) Materiality, sociomateriality, and socio-technical systems: What do these terms mean? How are they related? Do we need them? In: Leonardi PM, Nardi BA, Kallinikos J (eds) Materiality and organizing social interaction in a technological world. Oxford University Press, Oxford, pp 25-48

Leonardi PM (2013a) When does technology use enable network change in organizations? A comparative study of feature use and shared affordances. MIS Q 37:749-776

Leonardi PM (2013b) Theoretical foundations for the study of sociomateriality. Inf Organ 23:59-76. https:// doi.org/10.1016/j.infoandorg.2013.02.002

Leonardi PM, Barley SR (2008) Materiality and change: challenges to building better theory about technology and organizing. Inf Organ 18:159-176. https://doi.org/10.1016/j.infoandorg.2008.03.001

Leonardi PM, Rodriguez-Lluesma C (2013) Sociomateriality as a lens for design: imbrication and the constitution of technology and organization. Scand J Inf Syst 24:79-88

Luo X, Shen GQ, Fan S, Xue X (2011) A group decision support system for implementing value management methodology in construction briefing. Int J Proj Manag 29:1003-1017. https://doi.org/10.1016/j.ijpro man.2010.11.003

Majchrzak A, Markus ML (2012) Technology affordances and constraints in management information systems (MISs). In: Kessler E (ed) Encyclopedia of Management Theory. SAGE Publications, Ltd, Thousand Oaks, p 5

Manning PK (2008) The technology of policing: crime mapping, information technology, and the rationality of crime control. NYU Press, New York

Markus ML, Silver MS (2008) A foundation for the study of IT effects: a new look at DeSanctis and Poole's concepts of structural features and spirit. J Assoc Inf Syst 9:609-632. https://doi.org/10.17705/1jais. 00176

McGrath J (1984) Groups: interaction and performance. Prentice-Hall Inc, Englewood Cliffs

Medina H, Verhulst MJ, Rutkowski A-F (2015) Is it health information technology ? Task complexity and work substitution. In: Twenty-first americas conference on information systems, Puerto Rico, 2015, pp 1-13

Mendonça D, Beroggi GEG, Van Gent D, Wallace WA (2006) Designing gaming simulations for the assessment of group decision support systems in emergency response. Saf Sci 44:523-535. https://do i.org/10.1016/j.scci.2005.12.006

Miles MB, Huberman AM (1994) Qualitative data analysis: an expanded sourcebook. SAGE Publications, Thousand Oaks

Niemimaa M (2016) Sociomateriality and information systems research: quantum radicals and Cartesian conservatives. Data Base Adv Inf Syst 47:45-59

Nunamaker JF Jr, Romano NC, Briggs RO (2002) Increasing intellectual bandwidth: generating value from intellectual capital with information technology. Group Decis Negot II:69-82

Okoli J, Watt J, Weller G, Wong WBL (2016) The role of expertise in dynamic risk assessment: a reflection of the problem-solving strategies used by experienced fireground commanders. Risk Manag 18:4-25. https://doi.org/10.1057/rm.2015.20 
Orlikowski WJ (2007) Sociomaterial practices: exploring technology at work. Organ Stud 28:1435-1448. https://doi.org/10.1177/0170840607081138

Orlikowski WJ (2008) Using technology and constituting structures: a practice lens for studying technology in organizations. Organ Sci 11:404-428. https://doi.org/10.1287/orsc.11.4.404.14600

Orlikowski WJ, Scott SV (2008) Sociomateriality: challenging the separation of technology, work and organization. Acad Manag Ann 2:433-474. https://doi.org/10.1080/19416520802211644

Pentland BT, Rueter HH (1994) Organizational routines as grammars of action. Adm Sci Q 39:484-510. https://doi.org/10.2307/2393300

Pozzi G, Pigni F, Vitari C (2014) Affordance theory in the IS discipline: a review and synthesis of the literature. Twent Am Conf Inf Syst Savannah 2014:1-12

Rees J, Barkhi R (2001) The problem of highly constrained tasks in group decision support systems. Eur J Oper Res 135:220-229. https://doi.org/10.1016/S0377-2217(00)00323-4

Rossel PO, Herskovic V, Ormeño E (2016) Creating a family of collaborative applications for emergency management in the firefighting sub-domain. Inf Syst Front 18:69-84. https://doi.org/10.1007/s10796015-9575-0

Rutkowski A-F (2016) Work substitution: a Neo-Luddite look at software growth. IEEE Softw 33:101-104. https://doi.org/10.1109/MS.2016.73

Saavedra R, Earley PC, Van Dyne L (1993) Complex interdependence in task-performing groups. J Appl Psychol 78:61-72. https://doi.org/10.1037/0021-9010.78.1.61

Saunders C, Rutkowski AF, Pluyter J, Spanjers R (2016) Health information technologies: from hazardous to the dark side. J Assoc Inf Sci Technol 67:1767-1772. https://doi.org/10.1002/asi.23671

Scharf P, Binder A (1984) The badge and the bullet: police use of deadly force. Contemp. Sociol. 13:293

Scott SV, Orlikowski WJ (2012) Reconfiguring relations of accountability: materialization of social media in the travel sector. Acc Organ Soc 37:26-40. https://doi.org/10.1016/j.aos.2011.11.005

Scott SV, Orlikowski WJ (2013) Sociomateriality-taking the wrong turning? A response to Mutch. Inf Organ 23:77-80. https://doi.org/10.1016/j.infoandorg.2013.02.003

Scott SV, Orlikowski WJ (2014) Entanglements in practice: performing anonymity through social media. MIS Q 38:873-893

Simon H, Newell A (1973) Human problem solving. Contemp Sociol 2:169. https://doi.org/10.2307/2063 712

Smith DC, Skolnick JH, Fyfe JJ (1996) Above the law: police and the excessive use of force. Contemp Sociol 25:538

Sørensen C, Pica D (2005) Tales from the police: rhythms of interaction with mobile technologies. Inf Organ 15:125-149. https://doi.org/10.1016/j.infoandorg.2005.02.007

Stroshine M, Alpert G, Dunham R (2008) The influence of "working rules" on police suspicion and discretionary decision making. Police Q 11:315-337. https://doi.org/10.1177/1098611107313029

Sykes K, Macnaghten P (2013) Responsible innovation - Opening up dialogue and debate. In: Heintz M, Bessant J (eds) Responsible innovation: managing the responsible emergence of science and innovation in society. Wiley, London, pp 85-107

Ter Mors A, Valk J, Witteveen C (2005) An event-based task framework for disaster planning and decision support. In: Proceedings of the 2nd international ISCRAM conference, pp 151-153

Turoff M, Chumer M, Van de Walle BA, Yao X (2004) The design of a dynamic emergency response management information system (DERMIS). J Inf Technol Theory Appl 5:1-36

Tversky A, Kahneman D (1973) Availability: a heuristic for judging frequency and probability. Cogn Psychol 5:207-232. https://doi.org/10.1016/0010-0285(73)90033-9

Van de Walle B, Turoff M (2008) Decision support for emergency situations. Inf Syst E-bus Manag 6:295-316. https://doi.org/10.1007/s10257-008-0087-z

Van den Heuvel C, Alison L, Power N (2014) Coping with uncertainty: police strategies for resilient decision-making and action implementation. Cogn Technol Work 16:25-45. https://doi.org/10.1007/ s10111-012-0241-8

Van Fenema PC (2005) Collaborative elasticity and breakdowns in high reliability organizations: contributions from distributed cognition and collective mind theory. Cogn Technol Work 7:134-140. https://d oi.org/10.1007/s10111-005-0181-7

Van Gelderen BR, Bakker AB, Konijn EA, Demerouti E (2011) Daily suppression of discrete emotions during the work of police service workers and criminal investigation officers. Anxiety Stress Coping 24:515-537. https://doi.org/10.1080/10615806.2011.560665 
Van Osch W, Mendelson O (2011) A typology of affordances: Untangling sociomaterial interactions through video analysis. In: 32nd International Conference on Information System 2011, ICIS 2011 - Shanghai, China, pp 132-149

Verhulst MJ, Rutkowski A-F (2017) Catch me if you can: Technological constraints/affordances and mindfulness during collaborative police emergency response. In: Proceedings of the 50th Hawaii international conference on system sciences| 2017, pp 771-780

Vogus TJ, Sutcliffe KM (2007) The safety organizing scale. Med Care 45:46-54. https://doi.org/10.1097/0 1.mlr.0000244635.61178.7a

Vogus TJ, Sutcliffe KM, Weick KE (2010) Doing no harm: enabling, enacting, and elaborating a culture of safety in health care. Acad Manag Perspect 24:60-77. https://doi.org/10.5465/AMP.2010.55206385

Wilson KA, Burke CS, Priest HA, Salas E (2005) Promoting health care safety through training high reliability teams. Qual Saf Health Care 14:303-309. https://doi.org/10.1136/qshc.2004.010090

Wood RE (1986) Task complexity: definition of the construct. Organ Behav Hum Decis Process 37:60-82. https://doi.org/10.1016/0749-5978(86)90044-0

Yu L, Lai KK (2011) A distance-based group decision-making methodology for multi-person multi-criteria emergency decision support. Decis Support Syst 51:307-315. https://doi.org/10.1016/j.dss.2010.11.0 24

Zigurs I, Buckland BK (1998) A theory of task/technology fit and group support systems. MIS Q 22:313-334. https://doi.org/10.2307/249668 